\title{
IFMBE/CED recognition of certification/registration programs for clinical engineering practitioners
}

\section{By J. Wear}

Scientific Enterprises, Inc.

\begin{abstract}
The IFMBE/Clinical Engineering Division (IFMBE/CED) has recently established an International Credentialing Board (ICB) [https://ced.ifmbe.org/projects/ce-htm-credentialing.html] to recognize organizations that certify or register clinical engineering practitioners (CEPs). The ICB has 9 members appointed by the CED Board and these members are experienced Clinical Engineering Practitioners with several certified or registered. The ICB will maintain a list of recognized organizations that certify or register CEPs but will not maintain a list of the individuals certified/registered by these organizations. The National Examining Authority (NEA) that performs national certification/registration can submit information on their program to the ICB and request to be globally recognized. This will include detail information on the program and how it administers their certifying or registering their individuals. Once recognized a program will be subjected to renewal reviews every three years to assure that it is still a valid and compliant operational program.

Since there are yet no specific guidelines for programs to certify/register CEPs, the ICB will have to evaluate each NEA submission in detail. The ICB will need to determine that the individuals certified/registered are qualified practicing CEPs and the program is well managed and fulfills its objectives. To be qualified the NEA must have a set of By-Laws and a Code of Ethics amongst other requirements. Certification programs may be based on credentials only or programs based on exams and credentials. Registration programs may be based on credentials including experience. The recommendations are that certification/registration programs should meet individual countries needs and how clinical engineering is practiced in a country. In lieu of an engineering degree requirement the NEA may substitute experience history since not all clinical engineering practitioners have engineering degrees due to the lack of education opportunities in their local. The ICB will also aid professional groups that are trying to establish certification/registration programs for CEPs.

\section{Keywords - Clinical Engineering, Certification, Registration, Practitioner, Board, Clinical Engineer, Education.}

Copyright (C) 2021. This is an open-access article distributed under the terms of the Creative Commons Attribution License (CC BY): Creative Commons - Attribution 4.0 International - CC BY 4.0. The use, distribution or reproduction in other forums is permitted, provided the original author(s) and the copyright owner(s) are credited and that the original publication in this journal is cited, in accordance with accepted academic practice. No use, distribution or reproduction is permitted which does not comply with these terms.
\end{abstract}

\section{INTRODUCTION}

The Credentialing Project Team of the Clinical Engineering Division (CED) of IFMBE https://ced.ifmbe.org/ projects/ce-htm-credentialing.html worked for three years on the development and adoption of the framework for recognition of certification or registration programs for clinical engineering practitioners (CEPs). The previous work of the CED was examined. Next existing certification and registration programs for CEPs were reviews to determine if there were any common requirements and operations for the programs. There are major differences between certification and registration programs and significant differences in each of these approaches [link here] https://aamalegaleye.wordpress.com/2017/09/06/ registered-vs-certified-a-question-of-terminology/. It was 
determined that all of the major certification/registration programs for CEPs appeared to recognize only qualified CEPs. "IFMBE CED White Paper entitled "Certification/ Registration of Clinical Engineering Practitioners" James Wear was submitted 1 September 2017. http://cedglobal. org/wp-content/uploads/2018/06/CED-CertificationWhite-Paper-with-Annexes.pdf

The team that worked on this project represented different countries and different sections of the world. The present team members are listed here:

- James O. Wear (USA)

- Fabrola Martinez (Mexico)

- Mario Medvede (Croatia)

- Adrian Richards (Australia)

- Ewa Zalewska (Poland)

Since the members were scattered around the world, most of the meetings were by teleconferences. The team submitted the "Proposal for Recognizing Certification/ Registration Programs for Clinical Engineering Practitioners" to the IFMBE CED board in the summer 2019 and it was afterwards approved by this board.

\section{PROGRAM}

Clinical Engineering Practitioners perform many technology-related functions in the healthcare field and are called by different names even in the same country. Therefore it was necessary for the team to develop a definition for Clinical Engineering Practitioners for this project. The definition the team developed is:

"A clinical engineering practitioner is a Clinical Engineer, Biomedical Engineer, Healthcare Technology Manager, Clinical Engineering Technologist or Clinical/Biomedical Engineering Technician who practice technology management at a qualified level."

The purpose of the project was to develop a method for recognizing programs that certify or register clinical engineering practitioners and to facilitate evolution of common program elements. It will not be a program to recognize individuals who have been certified or registered as CEPs. The program will only develop a list of recognized programs and will not maintain a list of individuals certified or registered by the recognized programs. To maintain a list of individuals would be time consuming and therefore lead to the need for significant administrative and clerical time. This also would require significant additional funds.

The recognized programs will be expected to have an upto-date list of individuals they have certified/registered. A requirement for recognition will be that such a list be included and will stimulate individuals to maintain their certification/registration. The program should provide information on the certification/registration of individuals.

Recognized programs will be listed on the IFMBE/CED website with associated contact information. This will be an added benefit of their recognition. This will also provide a method that can be used to determine if an individual is certified/register by a recognized program.

The IFMBE/ CED Board has appointed the first International Credentialing Board (ICB). There are to be 9 members with some members being representative of the IFMBE/CED Board. Their service terms are to be the same as the IFMBE/CED Board members having staggered terms. They also are to be certified/registered or well qualified CEPs and representing the different parts of the world. The members in this first appointment are:

- Fabiola Martinez (Mexico) Co-Chair

- Li Bin (China) Co-Chair

- Ewa Zalwska (Poland)

- Jitender Sharma (India)

- Adrian Richards (Australia)

- Ricardo Silva (USA/Venezuela)

- Ashenafi Hussein (Ethiopia)

- Tomokazu Nagusawa (Japan)

- Riad Farah (Lebanon)

This ICB has representatives from 9 countries and 6 continents. Three or four are from countries that have programs that could seek recognition for their country's certification/registration program of CEPs.

The ICB will have to examine each application in detail to determine if it meets the requirements to be recognized. This will require the application for recognition to be very detailed and in specific format.

The sponsoring organizations of the certification/registration programs do not have to be members of IFMBE 
for the program to be able to apply for recognition. Since initially the number of programs applying is expected to be small, there will not be any fee to make application or to be recognized. This will also encourage programs to apply. The program will be administratively supported by the CED Secretariat and ICB board members. The CED may later initiate fees if the administrative costs becomes sufficient to justify it.

The organization that makes the application for recognition must be the one that operates the program and is called the National Examining Authority (NEA). The organization can be a professional organization, a government entity, an academic entity or some other form of a national or regional program. It can also be a for-profit program.

Requirements for a National Examining Authority to make a submission for recognition of their certification/ registration program are not as simple as it appears. Existing certification programs are very different and registration programs are very different from certification. Some basic requirements can be made for a submission and these follow in the next section.

\section{SUBMISSION REQUIREMENTS}

1. All submissions must be typed in English.

2. The submission must have a single contact person which is the chair person of the NEA or the Secretariat of the NEA. An address, email and phone number must be provided so they can be contacted if there are issues with their submission or administration. The ICB may at any time request additional information on a program through this individual.

3. The date the program was established will be submitted. There are no minimum years of operation since this might discourage new programs from developing. The critical factor is that a NEA is operational and has all the appropriate requirements for consideration of recognition. Also the programs will have a renewal every three years for their recognition. This will allow the ICB to recommend withdrawal of recognition of a program that has not fully developed.
4. The submission must have a sponsoring organization including how the program is involved with the sponsoring organization. This needs for the submission to be very specific for instance one of the major certification programs is sponsored by a national society, but it is independent of the sponsor for operation. The sponsor only provides administration support including budget but not fund raising.

5. The submission must provide all the names and affiliation of the NEA Board Members that are current, their terms, how they were selected and if they are certified/registered and by whom.

6. The submission must include the number of people currently certified/registered as Clinical Engineering Practitioners. The number should show the number in each Clinical Engineering group if there is more than one.

7. The National Examining Authority must be governed by a set of By-Laws included in the submission. If it is a problem for a new program to develop a legal set of By-Laws, the ICB should be able to provide an example of By-Laws to assist in their adoption.

8. Since ethics is a general important issue also for Clinical Engineering, the NEA must have a Code of Ethics that each certified/register person will abide by. The ICB can provide samples of Codes of Ethics to any organization applying.

The major part of the submission shall include a detail of the program including how it is financed. This part of the application can be different for each program and probably will be different for certified programs and registration programs. This shall include at least the following:

- When program started

- $\quad$ Program By-laws

- $\quad$ Forms for individual applications

- $\quad$ Forms for renewal applications

- How applications are reviewed

- If written or oral exams are required

- How many are certified/registered in Clinical Engineering 
- Years of experience required including type of experience

- Education requirements including any specific courses

- Fees required

There is no time limit on how long a program has been in operation, but it must be currently operating. No individual practitioner exams are required for a program to be considered for evaluation and some existing programs are based on experience and credentials. Programs like the US and Taiwan started based on experience and credentials and now require both written and oral exams. If the program has a handbook on how to become certified/registered CEP and renew, a copy must be provided. A program will normally have a renewal for certification/ registration and if so, this must be submitted. This will normally include the completion of continuing education CEUs, experience and professional activity. The renewal time period is usually for 3 to 5 years during which time the person must be practicing in the field.

The submission should include how the program is promoted in general to individuals in the field and to healthcare administrators. This would include how Clinical Engineering Practitioners are informed that the program exists in their area. This might be with presentations at their professional meetings as well as presentations at healthcare providers and administrator meetings. The program should be promoted to other healthcare providers such as administrators, physicians, nurses, technologists and to government agencies. This can be done with their interactions with these individuals. Offering to make presentations to their professional meetings and submitting articles about clinical engineering practitioners certification/registration to their professional journals.

After considering the application and the support documentation the ICB will determine if the application met the requirements and qualified for inclusion in the roster of ICB recognized NEA. The ICB may make specific recommendations for changes to a non-recognized program which can then resubmit an application.

A recognized program will be reviewed periodically to assure that it is still operating and if it has made any changes in operations. The ICB will have to determine how frequently this will occur and what will be required for demonstration of compliance.

\section{CONCLUSION}

The newly established International Credentialing Board currently conducts its business through virtual platform that support participation of its members from different parts of the world. It is working to encourage existing certification/registration programs to submit application for their program to be recognized. It is also developing materials and support that can aid in the development of new programs.

The ICB can be contacted through the IFMBE CED. 